\title{
Suppression of LPS-induced epithelial-mesenchymal transition by aqueous extracts of Prunella vulgaris through inhibition of the NF-kB/Snail signaling pathway and regulation of EMT-related protein expression
}

\author{
IN-HYE CHO ${ }^{1}$, EUN HYANG JANG ${ }^{1}$, DARONG HONG ${ }^{2}$, BOM JUNG ${ }^{1}$, MIN-JU PARK ${ }^{1}$ and JONG-HO KIM ${ }^{1}$ \\ ${ }^{1}$ Department of Pharmacy, and ${ }^{2}$ Department of Life and Nanopharmaceutical Science, \\ Graduate School, Kyung Hee University, Seoul 130-701, Republic of Korea
}

Received June 11, 2015; Accepted July 17, 2015

DOI: $10.3892 /$ or.2015.4218

\begin{abstract}
Epithelial-mesenchymal transition (EMT) is a pivotal event in the invasion and metastasis of cancer cells. Prunella vulgaris (PV) inhibits the proliferation of various cancer cells; however, its possible role in EMT has not been demonstrated. In the present study, we explored the effect of PV aqueous extract (PVAE), a typical medicine for decoction, on EMT. Lipopolysaccharide (LPS) induced EMT-like phenotype changes in cancer cell lines that enhanced cell migration and invasion. PVAE markedly inhibited these effects and produced accompanying changes in the expression of EMT markers, including decreased expression of $\mathrm{N}$-cadherin and vimentin, and increased expression of $\beta$-catenin. We found that PVAE effects on LPS-induced EMT were mediated by inhibition of the NF- $\kappa \mathrm{B} /$ Snail signaling pathway. Our findings provide new evidence that PVAE suppresses cancer invasion and migration by inhibiting EMT. Therefore, we suggest that PVAE is an effective dietary chemopreventive agent with antimetastatic activity against malignant tumors.
\end{abstract}

\section{Introduction}

The epithelial-mesenchymal transition (EMT), an important morphological event in which polarized epithelial cells convert to contractile and motile mesenchymal cells, is recognized as an important process during embryonic development and tissue organization (1). EMT leads to the generation of cancer cells with stem cell-like characteristics, increasing their self-renewal and tumor-initiating capabilities, and resistance to apoptosis and chemotherapy; collectively, these

Correspondence to: Professor Jong-Ho Kim, Department of Pharmacy, Graduate School, Kyung Hee University, 26 Kyungheedae-ro, Dongdaemun-gu, Seoul 130-701, Republic of Korea

E-mail: jonghokim@khu.ac.kr

Key words: prunella vulgaris, epithelial mesenchymal transition, migration, invasion, $\mathrm{NF}-\kappa \mathrm{B} /$ Snail signaling properties promote tumor cell invasion and metastasis (2). Given the previously established clinical importance of these EMT-associated processes, inhibition of EMT is an attractive therapeutic approach that could significant affect disease outcome, although it remains unclear which tumors should be treated and at what state of progression (3). Dietary chemoprevention using natural compounds such as herbal medicines has recently been highlighted as a safe method for preventing or suppressing the development of cancer, despite uncertainties about the molecular mechanisms of such compounds.

Prunella vulgaris (PV), commonly known as 'Ha-gocho' in Korea, it is a perennial herb that is widely distributed in East Asia and Europe. PV, which is effective in preventing or treating symptoms such as hypertension, inflammation, sore throat and fever, is commonly used as a dietary supplement worldwide. Phytochemical studies have indicated that PV contains oleanolic, betulinic, ursolic and rosmarinic acid; triterpenoids; flavonoids; tannins; and the anionic polysaccharide prumelline (4). Previous studies have reported that PV extracts possess various biological activities, including antimicrobial, anticancer and anti-inflammatory actions (5-8). Additionally, the aqueous extract of PV (PVAE) suppresses tumor cell invasion by regulating matrix metalloproteinase (MMP) expression $(9,10)$. However, an antimetastatic effect of PVAE in relation to EMT has not yet been reported.

In the present study, we hypothesized that PVAE, a typical medicine for decoction, may have a role as an inhibitor of EMT in cancer progression and thus could serve as a dietary chemopreventive agent against malignant tumors. We report that PVAE significantly inhibited the invasion and migration of lipopolysaccharide (LPS)-induced EMT in two metastatic cancer cell lines through downregulation of the $\mathrm{NF}-\kappa \mathrm{B} / \mathrm{Snail}$ signaling pathway. We propose that PVAE is a good candidate for use as a dietary chemopreventive agent with antimetastatic activity against malignant tumors.

\section{Materials and methods}

Materials and reagents. The PV used in the present study was kindly supplied by Professor Jung-Hye Choi (Kyung Hee 
University). Aqueous extraction procedures were performed by boiling $100 \mathrm{~g}$ PV in $500 \mathrm{ml}$ distilled water for $30 \mathrm{~min}$ and then filtering through Whatman filter paper No. 2 (Advantec, Tokyo, Japan). Subsquently, the filtrates were combined and evaporated under a vacuum and then lyophilized with a freeze dryer (Ilshine Lab, Suwon, Korea). The dry residue was stored at $-20^{\circ} \mathrm{C}$. MDA-MB-231 and SKOV-3 cells were maintained in Dulbecco's modified Eagle's medium (DMEM) supplemented with $10 \%$ fetal bovine serum (FBS) and $1 \%$ penicillin/stereptomycin antibiotics. The antibodies NF- $\kappa \mathrm{B}$ p65 subunit and $\beta$-actin were purchased from Santa Cruz Biotechnology (Santa Cruz, CA, USA), Snail was purchased from Cell Signalling Technology (Beverly, MA, USA), vimentin and $\beta$-catenin were purchased from Abcam (Cambridge, MA, USA), and $\mathrm{N}$-cadherin were purchased from BD Biosciences (San Jose, CA, USA).

Proliferation assay. All proliferation assays were based on the 3-[4,5-dimethythiazol-2-yl]-2,5-diphenyl tetrazolium bromide (MTT) method. Cells were seeded in a 96-well plate, $1 \times 10^{4}$ cells/well. After overnight culture, PVAE was added to the cells and further cultured for $24 \mathrm{~h}$. The media was removed and DMSO was added at MTT solubilization solution. Absorbance was measured at $550 \mathrm{~nm}$.

Colony forming assay. Single-cell suspensions of $5 \times 10^{3}$ cells were seeded into 6 -well plate and allowed to attach for $24 \mathrm{~h}$ at $37^{\circ} \mathrm{C}$ in culture medium. Cells were then treated with $100 \mu \mathrm{M}$ or 1,000 $\mu \mathrm{M}$ PVAE. After 10 days, colonies were fixed with $100 \%$ methanol for $10 \mathrm{~min}$ at room temperature and stained with $0.1 \%$ crystal violet. Plates were washed with PBS and were photographed.

Immunofluorescence staining. MDA-MB-231 cells were grown in 4-chamber slides in serum-free media, and were treated with LPS $(5 \mu \mathrm{g} / \mathrm{ml})$ or co-treated with LPS $(5 \mu \mathrm{g} / \mathrm{ml})$ and PVAE $(100 \mu \mathrm{M})$. After 24-h incubation, cells were fixed with $4 \%$ paraformaldehyde at $4^{\circ} \mathrm{C}$. Cells were washed with PBS containing $0.1 \%$ BSA and incubated with anti-N-cadherin antibody for $1 \mathrm{~h}$ followed by 1 -h incubation with fluorescencetagged secondary antibody, then counterstained with DAPI for 5 min. Cell images were captured at x200 magnification on a Leica fluorescence microscope.

Cell migration assay. Migration was assessed by a wound healing assay. Cells were seeded at $2 \times 10^{4}$ MDA-MB-231 and SKOV-3 cells/well and were cultured for $24 \mathrm{~h}$. After scraping the cell monolayer with a sterile micropipette tip, the wells were washed with PBS, and treated with LPS $(5 \mu \mathrm{g} / \mathrm{ml})$ or co-treated with LPS $(5 \mu \mathrm{g} / \mathrm{ml})$ and PVAE $(100 \mu \mathrm{M})$. The first image of each scratch was acquired at time zero. At $24 \mathrm{~h}$, each scratch was examined and captured at the same location and the healed area was measured.

Transwell invasion assay. The invasion of tumor cells was assessed in Transwell chambers equipped with $8-\mu \mathrm{m}$ pore size, $6.5 \mathrm{~mm}$ diameter polyvinylpyrrolidone-free polycarbonated membranes that were coated with $1 \mathrm{mg} / \mathrm{ml}$ fibronectin. The cells were seeded onto the upper wells at a concentration of $1 \times 10^{5}$ and MDA-MB-231 and SKOV-3 cells/well were cultured for $24 \mathrm{~h}$ following treatment with LPS $(5 \mu \mathrm{g} / \mathrm{ml})$ or co-treatment with LPS $(5 \mu \mathrm{g} / \mathrm{ml})$ and PVAE $(100 \mu \mathrm{M})$. The bottom chambers of the Transwell were filled with conditioned medium. After incubation for $24 \mathrm{~h}$, cells were fixed with $100 \%$ methanol for $10 \mathrm{~min}$ at room temperature, stained with $0.1 \%$ crystal violet and counted under a light microscope.

Western blotting. MDA-MB-231 and SKOV-3 cells were treated with with LPS $(5 \mu \mathrm{g} / \mathrm{ml})$ or co-treated with LPS $(5 \mu \mathrm{g} / \mathrm{ml})$ and PVAE $(100 \mu \mathrm{M})$ for $24 \mathrm{~h}$. After lysing cells with RIPA buffer, ptoteins were resolved by SDS-PAGE and immunoblotted using primary antibodies such as anti$\mathrm{N}$-cadherin, anti- $\beta$-catenin, anti-vimentin, anti-NF- $\kappa \mathrm{B}$ p65 subunit, anti-Snail and anti- $\beta$-actin antibody. After treatment with appropriate secondary antibodies, the immunoreactive bands were visualized by standard ECL method.

Statistical analysis. The results are presented as mean $\pm \mathrm{SE}$, and statistical comparisons between groups were carried out using one-way ANOVA followed by the Student's t-test.

\section{Results}

Effects of PVAE on the growth of human cancer cells in vitro. We initially examined the effect of PVAE on the proliferation of the human metastatic cancer cell lines MDA-MB-231 (breast cancer cells) and SKOV-3 (ovarian cancer cells). Cells were treated for $24 \mathrm{~h}$ with different concentrations of PVAE, and cell viability was measured by MTT assay. As shown in Fig. 1A, PVAE inhibited cell proliferation in a concentration-dependent manner, although the $\mathrm{IC}_{50}$ (the drug concentration that causes $50 \%$ growth inhibition) was different for MDA-MB-231 cells $(1094 \pm 7 \mu \mathrm{g} / \mathrm{ml})$ and SKOV-3 cells $(225 \pm 4 \mu \mathrm{g} / \mathrm{ml})$. The long-term effects of PVAE were determined by culturing MDA-MB-231 and SKOV-3 cells with or without PVAE for 10-15 days, and then performing colonyforming assays. At a concentration of $100 \mu \mathrm{g} / \mathrm{ml}$, PVAE did not show any significant effect, whereas $1,000 \mu \mathrm{g} / \mathrm{ml}$ PVAE almost completely inhibited colony formation (Fig. 1B). In light of the additional experiments, $100 \mu \mathrm{g} / \mathrm{ml}$ PVAE was considered a suitable concentration for use in subsequent experiments.

PVAE inhibits EMT-related increases in cell migration and invasion induced by LPS. LPS may act as an independent factor to trigger the EMT process, as has previously been reported by Chen and colleagues $(11,12)$. To determine whether PVAE inhibits LPS-induced EMT, which is associated with enhanced cellular progression, we monitored the effects of PVAE on LPS (5 $\mu \mathrm{g} / \mathrm{ml})$-induced migration and invasion. Cancer cell lines were treated with LPS alone, LPS plus PVAE, or PVAE alone, and wound-healing and fibronectin-based Transwell invasion assays were performed. LPS induced at least a 1.3-fold increase in migration, as determined by wound-healing assays, whereas treatment with $100 \mu \mathrm{g} / \mathrm{ml}$ PVAE inhibited this LPS-induced migration by an average of $60 \%$ (Fig. 2). Transwell invasion assays showed that treatment with LPS alone significantly increased the number of invasive cells compared with untreated control cells by 1.5 -fold or more. This LPS-induced increase in the number of invasive cells was significantly reduced by 
A

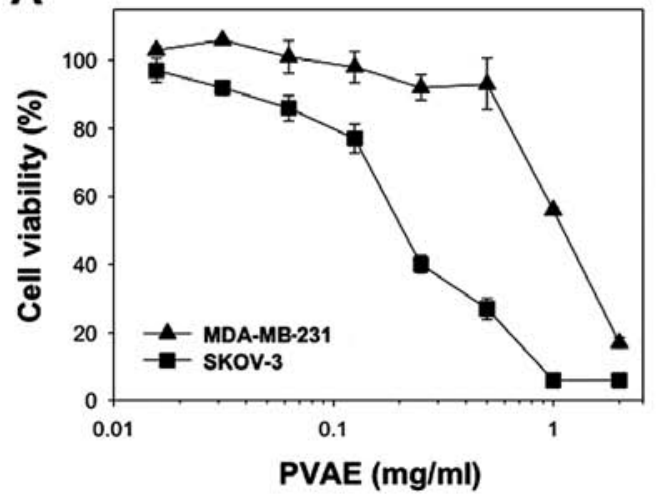

B

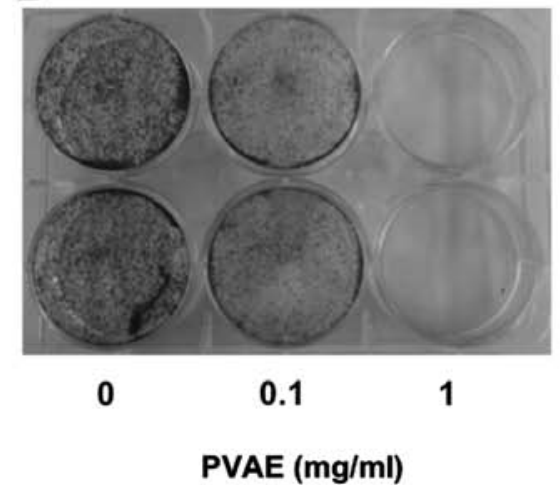

C

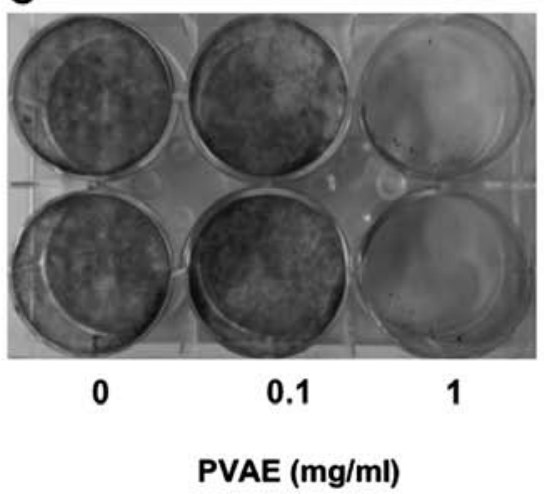

Figure 1. PVAE inhibits the growth of human cancer cells. (A) Antiproliferative effects of PVAE after 24 h in MDA-MB-231 and SKOV-3 cells. Cell proliferation was determined by MTT assay. Results are expressed as the mean \pm SD of three replicate measurements from a single representative experiment of three separate experiments. (B and C) The inhibitory effect of PVAE on colony formation by (B) MDA-MB-231 and (C) SKOV-3 cells. Representative photographs demonstrating colony formation are shown.

A

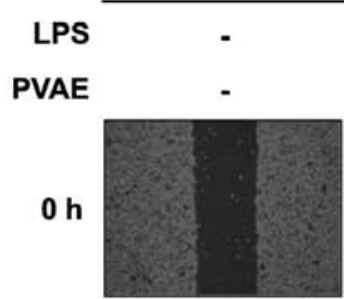

$24 \mathrm{~h}$
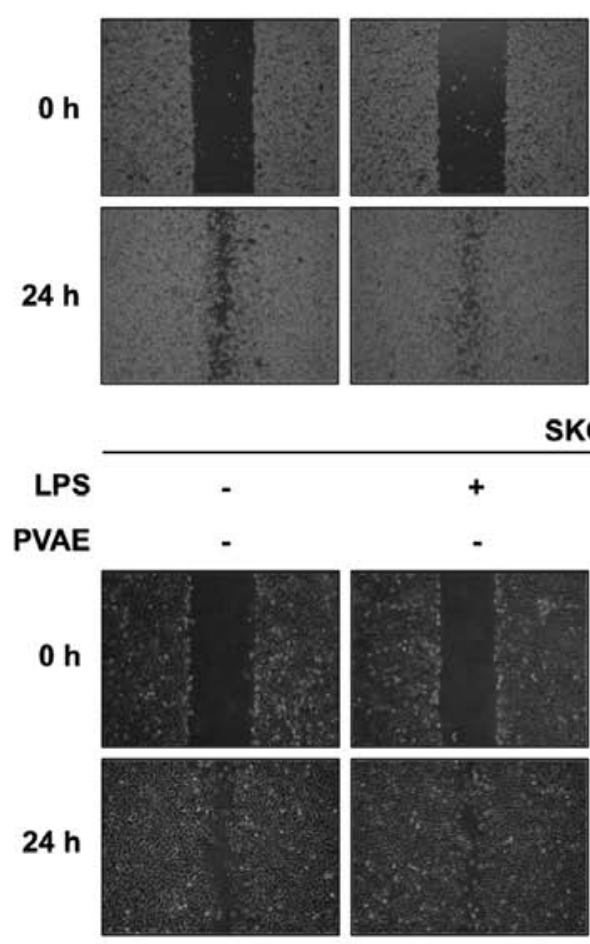

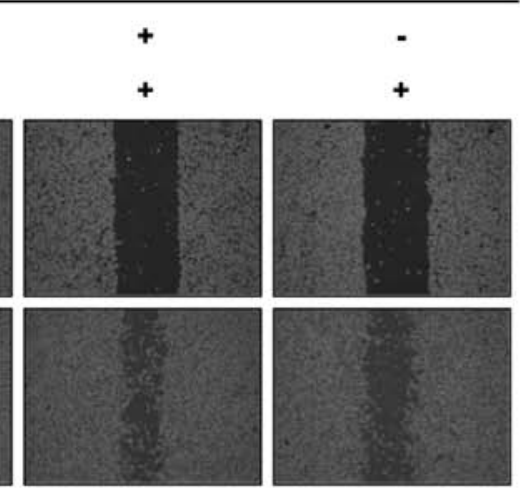

SKOV-3

MDA-MB-231

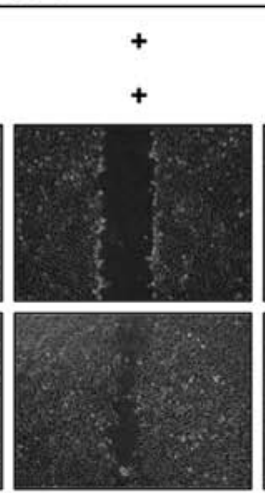

B
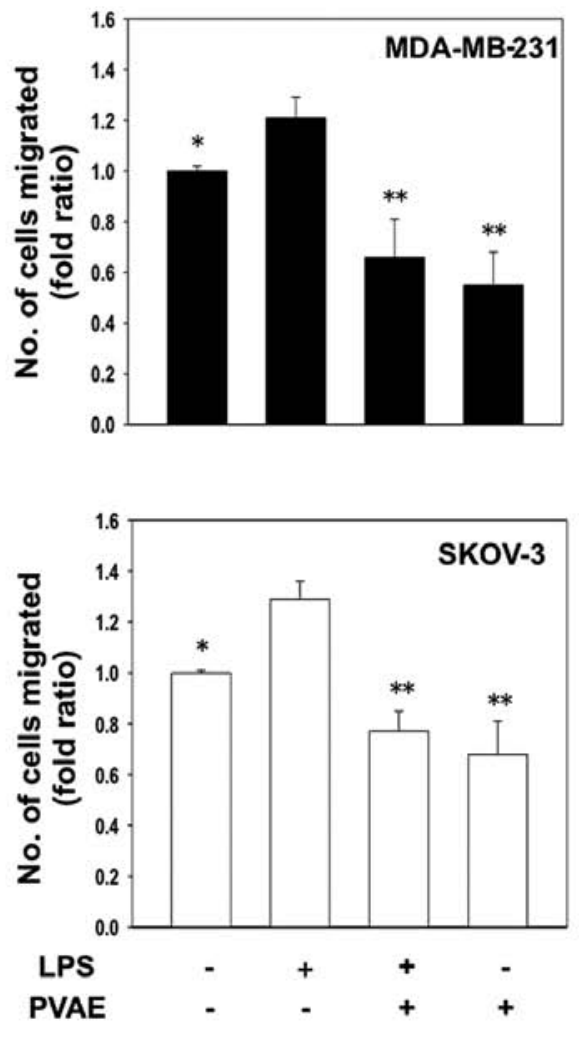

Figure 2. PVAE inhibits LPS-induced migration of MDA-MB-231 and SKOV-3 cells. (A) Representative images of wound healing were captured at the time of the scratch and $24 \mathrm{~h}$ later. (B) Cell migration into the wounded area was quantified as the fold ratio of wound healing ( $\mathrm{n}=5$; ${ }^{*} \mathrm{P}<0.05$, $^{* *} \mathrm{P}<0.01 \mathrm{vs}$. LPS-treated cells).

treatment with PVAE (Fig. 3). Collectively, these data suggest that PVAE inhibits the EMT-related increase in the invasiveness of human cancer cells induced by LPS.

PVAE inhibits the expression of markers of EMT in human cancer cells. To further investigate the effect of PVAE on LPS-induced EMT, we monitored the expression of the EMT-related proteins, $\mathrm{N}$-cadherin, $\beta$-catenin and vimentin by western blotting (Fig. 4A). $\beta$-catenin expression was signifi- cantly downregulated in LPS-treated cancer cells compared with controls, whereas N-cadherin and vimentin expression were upregulated. Notably, PVAE attenuated both downregulation of $\beta$-catenin and upregulation of $\mathrm{N}$-cadherin/vimentin, suggesting that it reversed LPS-induced EMT. We also examined $\mathrm{N}$-cadherin expression in cancer cells by immunofluorescence (Fig. 4B). Consistent with the western blotting results, $\mathrm{N}$-cadherin was highly expressed after LPS treatment, but was significantly decreased by co-treatment with PVAE. 
A

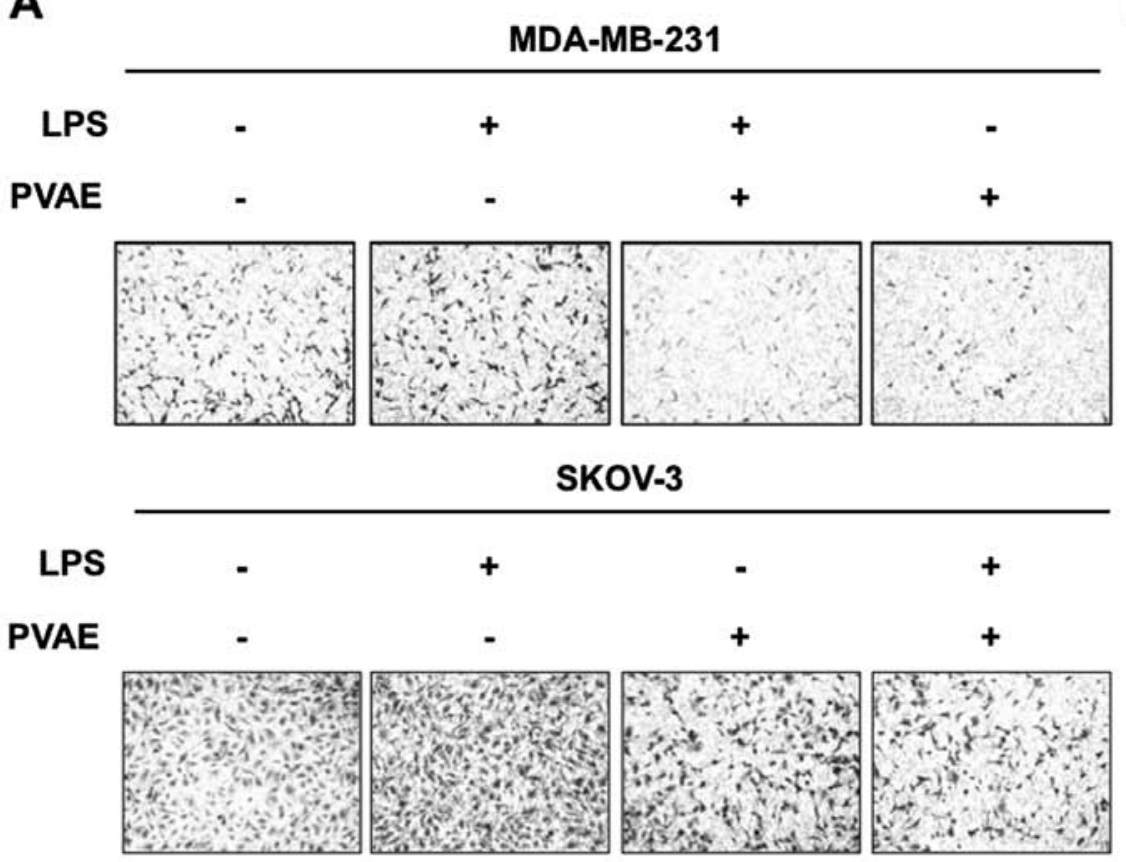

B
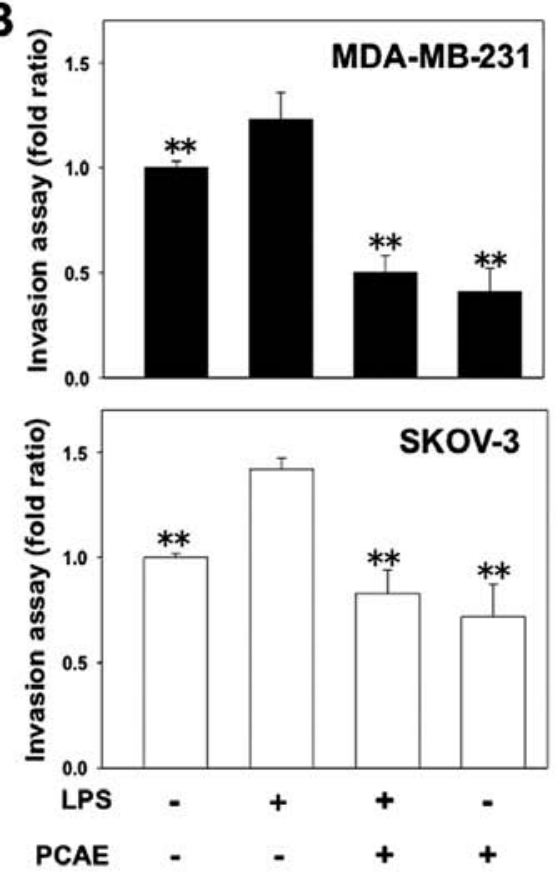

Figure 3. PVAE inhibits LPS-induced cell invasion. (A) Cell invasion was determined by Transwell assays. Representative photomicrographs of membraneassociated cells stained with crystal violet. (B) Cell invasion values were quantified as the fold ratio $\left(n=5 ;{ }^{*} \mathrm{P}<0.05,{ }^{* *} \mathrm{P}<0.01\right.$ vs. LPS-treated cells).

A

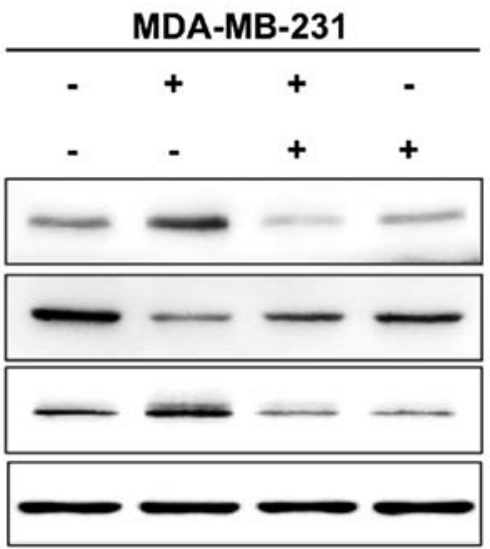

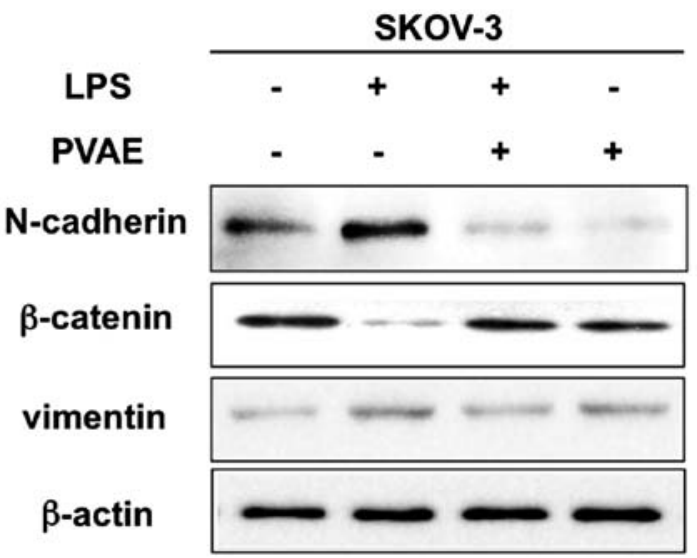

B
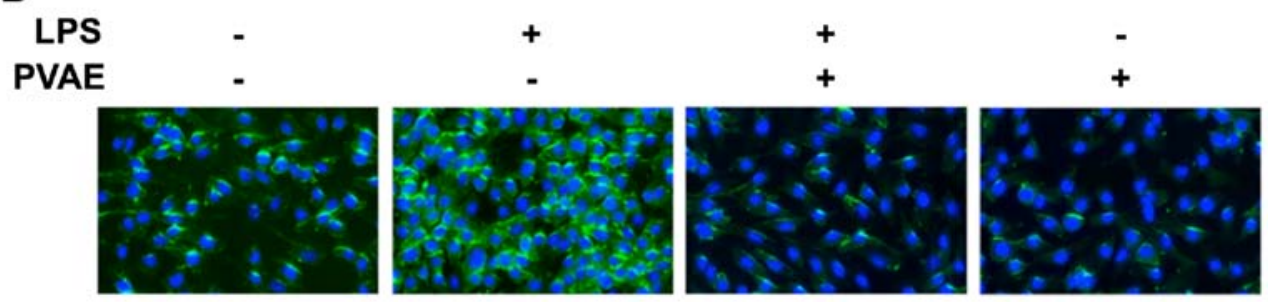

Figure 4. PVAE regulates the expression of EMT-related proteins. (A) N-cadherin, $\beta$-catenin, and vimentin protein expression in MDA-MB-231 and SKOV-3 cells was determined using western blot analysis. (B) MDA-MB-231 cells were immunostained with anti-N-cadherin antibody (green), and nuclei were counterstained with DAPI (blue) after PVAE treatment.

Taken together, western blotting and fluorescence imaging results imply that PVAE has an inhibitory effect on EMT.

$N F-\kappa B$ /Snail signaling is required for PVAE-mediated reversal of LPS-induced EMT marker expression. Numerous studies have reported that many drugs may inhibit the invasion and migration of cancer cells by suppressing NF- $\mathrm{kB}$ activation and Snail induction, suggesting that the NF- $\mathrm{kB}$ signaling pathway is critically involved in the acquisition of EMT through its downstream target, the transcription factor Snail. To determine whether the effects of PVAE on LPS-induced changes in EMT marker expression involve inhibition of NF- $\mathrm{kB} /$ Snail activa- 

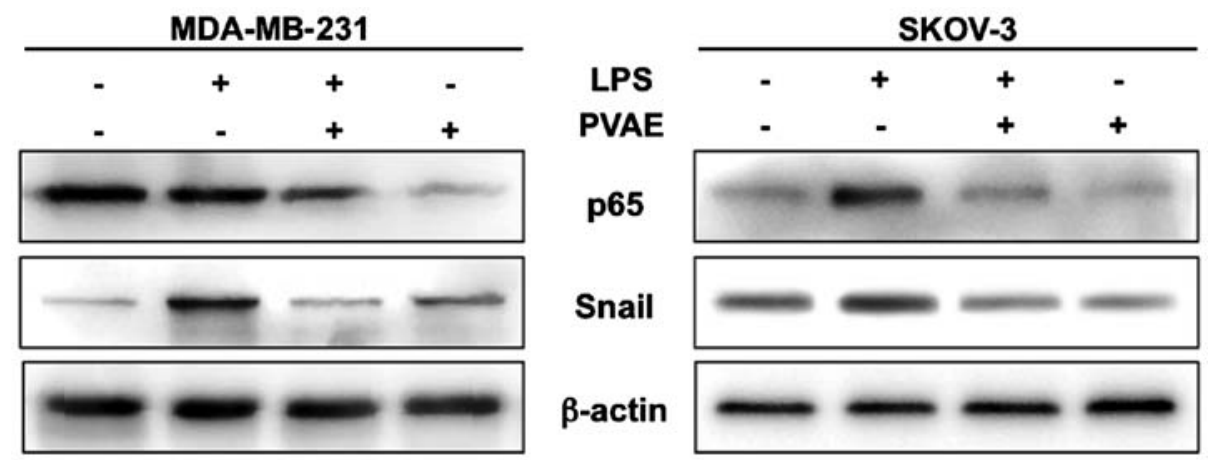

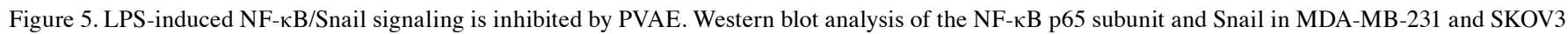
cells after treatment for $24 \mathrm{~h}$ with LPS, with and without PVAE.

tion, we monitored expression of the NF- $\kappa$ B p65 subunit and Snail by western blotting. As shown in Fig. 5, LPS significantly

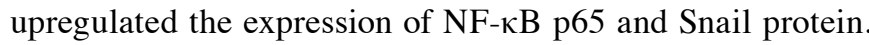
These effects were blunted by PVAE, suggesting that PVAE suppresses LPS-triggered EMT by counteracting NF- $\kappa \mathrm{B}$ p65 activation and Snail induction by LPS.

\section{Discussion}

Cancer cell metastasis is frequently associated with activation of EMT, which results in a loss of the cells' epithelial traits and acquisition of many properties of mesenchymal cells. The profound changes in cytoskeletal architecture that occur during EMT, together with a reduction in intercellular adhesion and an increase in motility, are fundamental to the metastatic process, enabling these cells to break through the basal membrane and migrate over long distances $(2,13)$. In addition, it was recently reported that the EMT process is related to the cancer stem cell-like properties and therapeutic resistance of cancer cells (14-16). EMT is a complex, stepwise phenomenon that is not only involved in embryonic development, but also in other physiological and pathological conditions, playing a role in enhancing the invasive and metastatic behavior of cancer cells. Therefore, inhibition of EMT is an attractive therapeutic approach that could have a significant effect on disease outcome.

As previously reported, LPS induces EMT in breast cancer cells, increasing their invasion and migration and resulting in enhanced lung metastasis (17). In the present study, we showed that LPS induces these typical features of EMT in various cancer cell types, and also promotes the characteristic decreases in $\beta$-catenin expression, and increases in $\mathrm{N}$-cadherin and vimentin expression. PVAE inhibited LPS-induced EMT, reversing the pattern of protein expression associated with invasion and migration. Additionally, we found that $\mathrm{NF}-\kappa \mathrm{B} /$ Snail signaling was required for LPS-induced EMT in various cancer cell types, suggesting a mechanism by which PVAE may act to inhibit cancer cell metastasis.

PV, a Labiate plant, is a traditional fever remedy, and more recently has been used to treat tuberculosis, thyroid gland swelling, jaundice, infectious hepatitis, bacillary dysentery, pleuritis, hypertension and cancer (18). PV has been highlighted in the dietary supplements research field as an anticancer agent that has been reported to exert strong anti- tumor effects by promoting apoptosis and regulating the cell cycle (19-21). Although some researchers have reported that PV and rosmarinic acid extracted from PV suppress cancer metastasis $(9,22,23)$, this action has not been linked to an EMT-dependent mechanism. To the best of our knowledge, the present study is the first to demonstrate that the antimetastatic effects of PV are associated with the EMT process in cultured human cancer cells, suggesting a new dietary chemopreventive role of PV in inhibiting the progression of EMT-related cancer metastasis.

In the present study, we showed that PVAE inhibited LPS-induced EMT, determined by monitoring changes in cell migration and invasion, and expression of cell-cell adhesion proteins and EMT-related proteins like $\mathrm{N}$-cadherin. Cadherins are transmembrane glycoproteins that mediate $\mathrm{Ca}^{2+}$-dependent cell-cell adhesion (24). N-cadherin, typically expressed by mesenchymal cells and overexpressed in some cancer cells, is correlated with enhanced invasiveness (25). Thus, the gain of $\mathrm{N}$-cadherin expression in cancer cells have functional significance for cancer progression and metastasis (26). PVAE also regulated the expression of other EMT-related proteins, including $\beta$-catenin and vimentin, resulting in inhibition of cell migration and invasion. $\beta$-catenin, a transcription factor in the Wnt signaling pathway involved in the regulation of cell adhesion, is typically more abundant in epithelial-like cells (27). Vimentin is an intermediate filament typically found in non-epithelial and mesenchymal cells (28).

Our data also demonstrated that the mechanism of action of PV may involve suppression of $N F-\kappa B /$ Snail signaling. $\mathrm{NF}-\kappa \mathrm{B}$ is a structurally conserved family of dimeric transcription factors that plays pivotal roles in maintaining an invasive phenotype as well as promoting carcinogenesis $(29,30)$. It also plays a central role in EMT through direct activation of the transcription of Snail, which has been established as a critical mediator of EMT (31). Consistent with the role of NF- $\kappa \mathrm{B}$ as an upstream regulator of Snail expression, inhibition of $N F-\kappa B$ reverses the induction of Snail mRNA during EMT (32). Our results support these previous findings and provide a mechanistic basis for the inhibition of tumor progression by PV as well as PVAE.

In conclusion, we demonstrated that PVAE inhibition of tumor invasion and migration is associated with the EMT process during tumor progression, and is possibly mediated by suppressing $\mathrm{NF}-\kappa \mathrm{B} /$ Snail signaling and regulating the 
expression of $\mathrm{N}$-cadherin, $\beta$-catenin and vimentin-important downstream EMT markers. Although further in vivo studies are needed to establish the potential of PVAE as an anticancer therapeutic agent, we suggest that PVAE is an effective dietary chemopreventive agent with antimetastatic activity against malignant tumors.

\section{Acknowledgements}

The present study was supported by the Traditional Korean Medicine R\&D program funded by the Ministry of Health \& Welfare through the Korea Health Industry Development Institute (HI14C05830000) and by the Basic Science Research Program through the National Research Foundation of Korea (NRF) funded by the Ministry of Education (2014R1A1A2057861).

\section{References}

1. Kong D, Li Y, Wang Z and Sarkar FH: Cancer stem cells and epithelial-to-mesenchymal transition (EMT)-phenotypic cells: Are They Cousins or Twins? Cancers (Basel) 3: 716-729, 2011.

2. Thiery JP, Acloque H, Huang RY and Nieto MA: Epithelialmesenchymal transitions in development and disease. Cell 139: 871-890, 2009.

3. Polyak K and Weinberg RA: Transitions between epithelial and mesenchymal states: Acquisition of malignant and stem cell traits. Nat Rev Cancer 9: 265-273, 2009.

4. Xu HX, Lee SH, Lee SF, White RL and Blay J: Isolation and characterization of an anti-HSV polysaccharide from Prunella vulgaris. Antiviral Res 44: 43-54, 1999.

5. Hwang YJ, Lee EJ, Kim HR and Hwang KA: In vitro antioxidant and anticancer effects of solvent fractions from Prunella vulgaris var. lilacina. BMC Complement Altern Med 13: 310, 2013

6. Park SH, Koo HJ, Sung YY and Kim HK: The protective effect of Prunella vulgaris ethanol extract against vascular inflammation in TNF- $\alpha$-stimulated human aortic smooth muscle cells BMB Rep 46: 352-357, 2013.

7. Psotová J, Kolár M, Sousek J, Svagera Z, Vicar J and Ulrichová J: Biological activities of Prunella vulgaris extract. Phytother Res 17: 1082-1087, 2003

8. Yoon MY, Choi GJ, Choi YH, Jang KS, Park MS, Cha B and Kim JC: Effect of polyacetylenic acids from Prunella vulgaris on various plant pathogens. Lett Appl Microbiol 51: 511-517, 2010.

9. Choi JH, Han EH, Hwang YP, Choi JM, Choi CY, Chung YC, Seo JK and Jeong HG: Suppression of PMA-induced tumor cell invasion and metastasis by aqueous extract isolated from Prunella vulgaris via the inhibition of NF-kappaB-dependent MMP-9 expression. Food Chem Toxicol 48: 564-571, 2010.

10. Kim SH, Huang CY, Tsai CY, Lu SY, Chiu CC and Fang K: The aqueous extract of Prunella vulgaris suppresses cell invasion and migration in human liver cancer cells by attenuating matrix metalloproteinases. Am J Chin Med 40: 643-656, 2012.

11. Chen MC, Chang WW, Kuan YD, Lin ST, Hsu HC and Lee CH: Resveratrol inhibits LPS-induced epithelial-mesenchymal transition in mouse melanoma model. Innate Immun 18: 685-693, 2012.

12. Huang T, Chen Z and Fang L: Curcumin inhibits LPS-induced EMT through downregulation of NF- $\mathrm{BB}$-Snail signaling in breast cancer cells. Oncol Rep 29: 117-124, 2013.

13. Kalluri R and Weinberg RA: The basics of epithelial-mesenchymal transition. J Clin Invest 119: 1420-1428, 2009.

14. Herschkowitz JI, Zhao W, Zhang M, Usary J, Murrow G, Edwards D, Knezevic J, Greene SB, Darr D, Troester MA, et al: Comparative oncogenomics identifies breast tumors enriched in functional tumor-initiating cells. Proc Natl Acad Sci USA 109: 2778-2783, 2012.
15. Iliopoulos D, Lindahl-Allen M, Polytarchou C, Hirsch HA, Tsichlis PN and Struhl K: Loss of miR-200 inhibition of Suz12 leads to polycomb-mediated repression required for the formation and maintenance of cancer stem cells. Mol Cell 39: 761-772, 2010.

16. Li QQ, Xu JD, Wang WJ, Cao XX, Chen Q, Tang F, Chen ZQ, Liu XP and Xu ZD: Twist1-mediated adriamycin-induced epithelial-mesenchymal transition relates to multidrug resistance and invasive potential in breast cancer cells. Clin Cancer Res 15: 2657-2665, 2009.

17. Wu Y, Deng J, Rychahou PG, Qiu S, Evers BM and Zhou BP: Stabilization of snail by NF-kappaB is required for inflammationinduced cell migration and invasion. Cancer Cell 15: 416-428, 2009.

18. Kim HI, Quan FS, Kim JE, Lee NR, Kim HJ, Jo SJ, Lee CM, Jang DS and Inn KS: Inhibition of estrogen signaling through depletion of estrogen receptor alpha by ursolic acid and betulinic acid from Prunella vulgaris var. lilacina. Biochem Biophys Res Commun 451: 282-287, 2014.

19. Blinman P, Alam M, Duric V, McLachlan SA and Stockler MR: Patients' preferences for chemotherapy in non-small-cell lung cancer: A systematic review. Lung Cancer 69: 141-147, 2010.

20. Feng L, Jia X, Zhu M, Chen Y and Shi F: Chemoprevention by Prunella vulgaris L. extract of non-small cell lung cancer via promoting apoptosis and regulating the cell cycle. Asian Pac J Cancer Prev 11: 1355-1358, 2010.

21. Feng L, Jia XB, Jiang J, Zhu MM, Chen Y, Tan XB and Shi F: Combination of active components enhances the efficacy of Prunella in prevention and treatment of lung cancer. Molecules 15: 7893-7906, 2010.

22. Xu Y, Jiang Z, Ji G and Liu J: Inhibition of bone metastasis from breast carcinoma by rosmarinic acid. Planta Med 76: 956-962, 2010.

23. Xu Y, Xu G, Liu L, Xu D and Liu J: Anti-invasion effect of rosmarinic acid via the extracellular signal-regulated kinase and oxidation-reduction pathway in Ls174-T cells. J Cell Biochem 111: 370-379, 2010.

24. van Roy F and Berx G: The cell-cell adhesion molecule E-cadherin. Cell Mol Life Sci 65: 3756-3788, 2008.

25. Nguyen PT, Kudo Y, Yoshida M, Kamata N, Ogawa I and Takata T: $\mathrm{N}$-cadherin expression is involved in malignant behavior of head and neck cancer in relation to epithelial-mesenchymal transition. Histol Histopathol 26: 147-156, 2011.

26. Araki K, Shimura T, Suzuki H, Tsutsumi S, Wada W, Yajima T, Kobayahi T, Kubo N and Kuwano H: E/N-cadherin switch mediates cancer progression via TGF- $\beta$-induced epithelial-tomesenchymal transition in extrahepatic cholangiocarcinoma. $\mathrm{Br}$ J Cancer 105: 1885-1893, 2011.

27. Huang J, Xiao D, Li G, Ma J, Chen P, Yuan W, Hou F, Ge J, Zhong M, Tang Y, et al: EphA2 promotes epithelial-mesenchymal transition through the Wnt/ $\beta$-catenin pathway in gastric cancer cells. Oncogene 33: 2737-2747, 2014.

28. Liu Z, Chen L, Zhang X, Xu X, Xing H, Zhang Y, Li W, Yu H, Zeng $\mathrm{J}$ and Jia J: RUNX3 regulates vimentin expression via miR-30a during epithelial-mesenchymal transition in gastric cancer cells. J Cell Mol Med 18: 610-623, 2014.

29. Ennen M, Klotz R, Touche N, Pinel S, Barbieux C, Besancenot V, Brunner E, Thiebaut D, Jung AC, Ledrappier S, et al: DDB2: A novel regulator of NF- $\kappa \mathrm{B}$ and breast tumor invasion. Cancer Res 73: 5040-5052, 2013.

30. Wu K, Zeng J, Li L, Fan J, Zhang D, Xue Y, Zhu G, Yang L, Wang $X$ and He D: Silibinin reverses epithelial-to-mesenchymal transition in metastatic prostate cancer cells by targeting transcription factors. Oncol Rep 23: 1545-1552, 2010.

31. Chua HL, Bhat-Nakshatri P, Clare SE, Morimiya A, Badve S and Nakshatri H: NF-kappaB represses E-cadherin expression and enhances epithelial to mesenchymal transition of mammary epithelial cells: Potential involvement of ZEB-1 and ZEB-2. Oncogene 26: 711-724, 2007.

32. Min C, Eddy SF, Sherr DH and Sonenshein GE: NF-kappaB and epithelial to mesenchymal transition of cancer. J Cell Biochem 104: 733-744, 2008. 